\title{
Lead Site rV2
}

National Cancer Institute

\section{Source}

National Cancer Institute. Lead Site rV2. NCI Thesaurus. Code C90411.

A unipolar precordial lead placed at the second intercostal space to the left of the sternum. 